\title{
MPTP-Induced Neurotoxicity and the Quest for a Preventative Therapy for Parkinson's Disease
}

\author{
J.C.S. Furtado and Michael F. Mazurek
}

\begin{abstract}
Less than 10 years have passed since the discovery that 1-methyl-4-phenyl-1,2,3,6-tetrahydropyridine (MPTP) is capable of producing parkinsonism in both humans and non-human primates. In that time, there has been considerable interest in the possibility that the pathogenesis of idiopathic Parkinson's disease (PD) might involve a process analogous to that of MPTP toxicity. One hypothesis holds that PD might arise, at least in part, from exposure to an MPTP-like environmental toxin. Rapid progress has been made towards elucidating the precise mechanism by which MPTP exerts toxicity, and clarifying the relationship of MPTP toxicity to idiopathic PD. The goal of these efforts is to develop a therapy that inhibits the underlying disease process in PD.
\end{abstract}

RÉSUMÉ: Neurotoxicité induite par le MPTP et recherche d'une thérapie préventive pour la maladie de Parkinson. Moins de 10 ans se sont écoulés depuis la découverte que la 1-méthyl-4-phenyl-1,2,3,6-tetrahydropyridine (MPTP) peut produire le parkinsonisme chez les primates humains et non-humains. Depuis ce temps, la possibilité que la pathogenèse de la maladie de Parkinson idiopathique (MP) pouvait impliquer un processus analogue à celui de la toxicité du MPTP a suscité un intérêt considérable. Selon une hypothèse, la MP pourrait résulter, du moins en partie, d'une exposition à une toxine environnementale similaire au MPTP. Des progrès rapides ont été accomplis pour élucider le mécanisme précis de la toxicité du MPTP et clarifier la relation entre la toxicité du MPTP et la MP idiopathique. Le but de cex efforts est de développer une thérapie qui inhibe le processus sous-jacent à la MP.

Can. J. Neurol. Sci. 1991; 18: 77-82

Recent reports have indicated that deprenyl, an inhibitor of the catecholamine catabolic enzyme monoamine oxidase, type B (MAO-B), may delay the onset of disability associated with early, otherwise untreated, cases of idiopathic Parkinson's disease (PD). 1,2 The efficacy of deprenyl in the treatment of PD has long been recognized in Europe ${ }^{3-6}$ where its beneficial effects have generally been ascribed to an increase in the dopamine content of the presynaptic nerve terminals. ${ }^{3,7}$ One interpretation of the recent North American results is that deprenyl might not simply provide symptomatic therapy, but might actually interfere with the underlying pathogenetic mechanisms of PD and thereby slow the progression of the disease itself.1,2 This notion had originally been proposed by Birkmayer and colleagues in the mid-1980s $\mathrm{s}^{3.8}$ but, until recently, lacked compelling supportive evidence from a prospective trial.

\section{The MPTP Model of Parkinsonism}

Much of the impetus for proceeding with randomized clinical trials of deprenyl originated with the observation that the meperidine derivative 1-methyl-4-phenyl-1,2,3,6-tetrahydropyridine (MPTP) could produce a clinical syndrome strikingly similar to idiopathic PD.9.10 Subsequent animal experiments showed that primates treated with MPTP develop bradykinesia, rigidity and tremor (although the tremor tends to resemble a cerebellar action tremor rather than the classic resting tremor of PD: $c f . C D$ Marsden, as quoted in reference 11). Neuropathological examination reveals damage to the dopaminergic neurons of the substantia nigra and, to a lesser extent, the noradrenergic cells of the locus coeruleus; this damage is accompanied by eosinophilic intraneuronal inclusion bodies, which resemble Lewy bodies. 12

From the Division of Neuroscience, Department of Biomedical Sciences (JCSF, MFM) and Division of Neurology, Department of Medicine (MFM), McMaster University Medical Centre, Hamilton

Received April 6, 1990. Accepted in final form October 24, 1990

Reprint requests to: Dr. Michael F. Mazurek, Neurology 4U2, McMaster University, Medical Centre, 1200 Main Street West, Hamilton, Ontario, Canada L8N $3 Z 5$ 
Neurochemical analysis demonstrates depletion of dopaminergic markers from the nigrostriatal tract, ${ }^{13-17}$ and, to a lesser extent, from the mesolimbic system, the mesocortical system and the retina. ${ }^{17-19}$ Noradrenergic indices are also decreased in MPTPtreated primates ${ }^{20,21}$ while the neuropeptide profile following MPTP treatment less consistently mimics that observed in PD. ${ }^{13}$

The remarkable similarities between idiopathic PD and the syndrome induced by MPTP have focused attention on the pathophysiology involved in MPTP-induced toxicity. The postulated steps are outlined in Figure 1, and are described below in detail.

Step 1: Oxidation of MPTP. MPTP can readily cross the blood-brain barrier, but the substance itself is not toxic. ${ }^{22}$ Instead, toxicity is thought to be produced by 1 -methyl-phenylpyridinium (MPP+), a metabolite of MPTP. The first step in this process is the oxidation of MPTP to 1-methyl-phenyl-dihydropyridinium (MPDP), via MAO-B; MPDP then spontaneously oxidizes to MPP+. ${ }^{23.24}$ The administration of nonspecific (e.g. pargyline) or specific (e.g. deprenyl, MD240928) blockers of MAO-B activity prior to MPTP treatment prevents the conversion of MPTP to MPP+ and results in attenuation of toxicity, both in vivo and in vitro. ${ }^{25-28}$ Specific blockers of MAO-A activity, on the other hand, are unable to inhibit MPTP-induced toxicity. ${ }^{25,26}$ Interestingly, the catecholaminergic neurons of the substantia nigra and locus coeruleus do not appear to contain appreciable quantities of MAO-B and therefore may not be capable of oxidizing MPTP.29-32 Instead, MPTP is thought to be metabolized to MPP+ within astrocytes and, to a much lesser extent, within serotonergic neurons, ${ }^{28,32-35}$ the two central nervous system cell classes in which MAO-B is predominantly located ${ }^{30,3} 1$

Step 2: MPP+ in the Extracellular Fluid. Following the oxidation of MPTP, MPP+ is found within the extracellular fluid, 28,35 although the precise mechanism by which it gets there has not been clarified. One possibility is that MPDP is released from astrocytes/serotonergic neurons and oxidized to MPP+ in the extracellular space. Another is that the conversion of MPDP to MPP+ takes place within astrocytes/serotonergic neurons, with subsequent secretion of MPP+ into the extracellular fluid.

Step 3: Uptake of MPP+. Once MPP+ is present within the extracellular fluid, it is taken up into catecholaminergic neurons via the appropriate high-affinity uptake systems. ${ }^{36.37}$ Pretreatment with specific (GBR 13098, maprotiline) or nonspecific (mazindol, nomifensine) dopamine and noradrenaline uptake inhibitors results in attenuation of MPTP-induced dopamine and noradrenaline depletions. 25,27,38-41 Conversely, prior inhibition of catecholamine vesicular transport with reserpine or tetrabenazine potentiates MPTP-induced dopamine depletions, presumably because MPP+ is not sequestered into storage vesicles and is therefore free to exert its toxic effects within the cytosol. 42

Step 4: Interaction with Neuromelanin. Neuromelanin (NM), a granular pigment found in selected areas of the mammalian brainstem and dorsal root ganglia, 43 plays an important role in the cytotoxic effects of MPP+. It has been suggested that NM binds to MPP+, thus preventing its clearance from the brain, and that the gradual release of MPP+ from this intracellular depot is crucial in the production of cytotoxicity. 44 Pretreatment of primates with the antimalarial drug chloroquine results in attention of MPTP-induced toxicity, ${ }^{44}$ presumably because chloroquine binds to NM, and thereby interferes with the binding of MPP+ to NM.44-47

The presence of high concentrations of NM in the primate and human, but not in the rodent, ${ }^{43}$ may help account for the extraordinary variability in species vulnerability to MPTP: 0.33 -

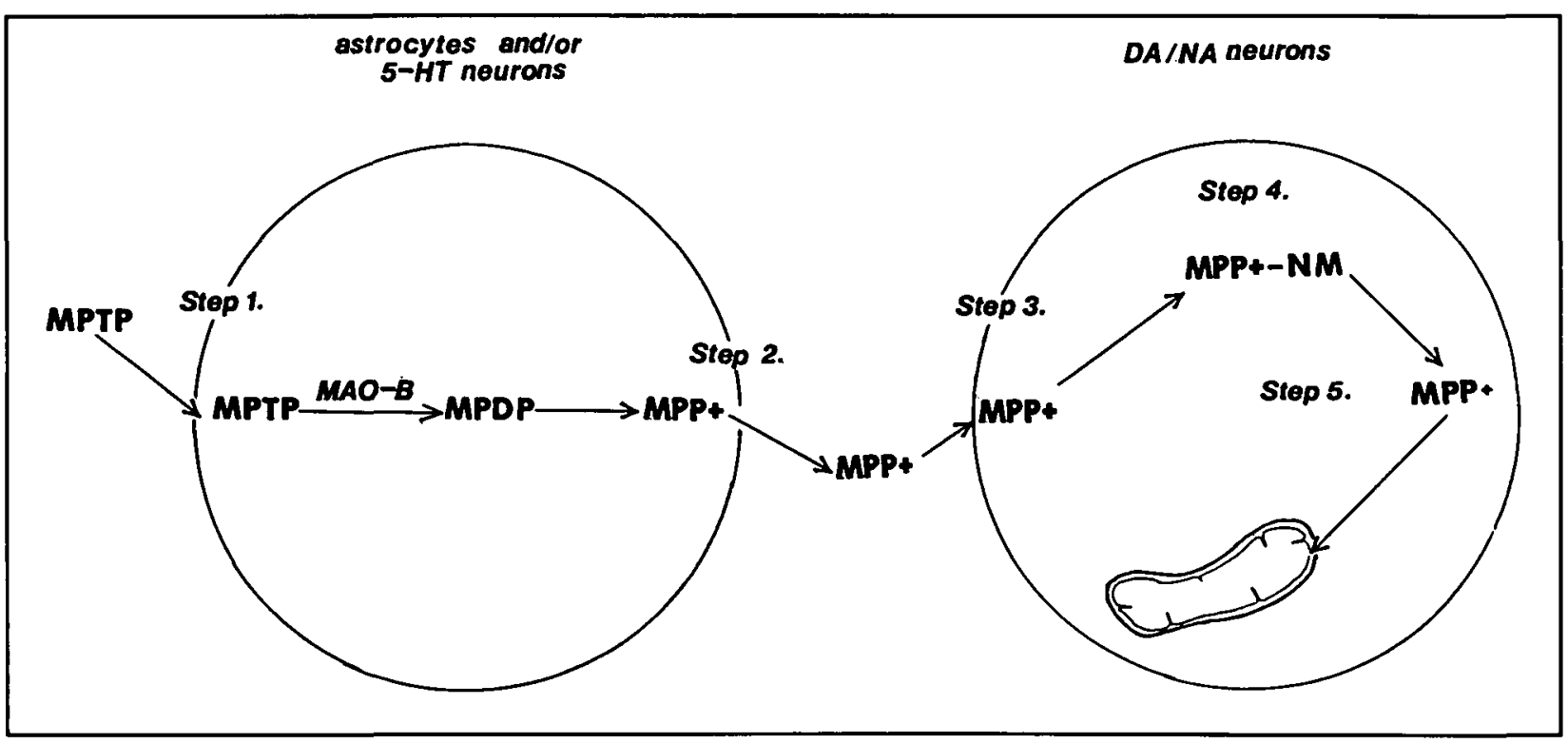

Figure I - Postulated Steps of MPTP-Induced Cytotoxicity. Step L MPTP crosses the blood-brain barrier and is taken up into astrocytes andlor serotonergic neurons where it is metabolized into MPDP via MAO-B. MPDP then spontaneously oxidizes to MPP+. Step 2. MPP+ is released from astrocytes/serotonergic neurons and enters the extracellular space. Alternatively, MPDP may be released from astrocytes/serotonergic neurons, with conversion to MPP+occurring in the extracellular space. Step $3 . M P P+i s$ taken up into dopaminergic/noradrenergic neurons. Step 4. MPP + binds to neuromelanin (NM). Step.5. MPP+ is released from NM, and taken up into mitochondria, where it interferes with the synthesis of ATP. 
$3.0 \mathrm{mg} / \mathrm{kg}$ of MPTP administered once per day for a few days produces permanent depletion of striatal dopaminergic markers in primates, ${ }^{20.48-50}$ while $10-50 \mathrm{mg} / \mathrm{kg}$ of MPTP administered several times per day over a few days results in only transient suppression of dopaminergic indices in rodents. ${ }^{14,15}$ The tendency of NM to accumulate with age may also partially explain why older animals are more susceptible than younger animals to the toxic effects of MPTP. 43,44

Step 5: Induction of Cell Death. The final step in MPTPinduced toxicity is thought to involve interference with mitochondrial respiration. MPP+ is taken up into the mitochondria via an energy-dependent uptake system (normally used for the uptake of pyruvate), resulting in the concentration of MPP+ within the mitochondrial matrix. MPP+ inhibits Complex I, a complicated membrane-bound system which catalyzes the transfer of electrons from NADH to ubiquinone (coenzyme Q). This may result in a bioenergetic deficiency if the electron transport chain is sufficiently blocked to inhibit oxidative phosphorylation and decrease the synthesis of ATP. ${ }^{51-53}$ Alternatively, relatively high-energy electrons diverted from the electron transport chain may go on to generate cytotoxic free radicals (see below). Either of these processes could lead to cell death. It was recently reported that Complex I is defective in patients with idiopathic PD, 54,55 reinforcing the similarities between PD and MPTPinduced parkinsonism.

Another potential mechanism of cell death in both MPTPinduced toxicity and idiopathic PD is through the generation of cytotoxic free radicals. It is known that the amount of NM in human brain increases with age, perhaps as a result of oxidation of catecholamines. ${ }^{43,56}$ The oxidation of dopamine or MPTP by MAO results in the formation of hydrogen peroxide $\left(\mathrm{H}_{2} \mathrm{O}_{2}\right)$. Transition metals such as iron (II) interact with hydrogen peroxide, leading to the production of free radicals such as the highly reactive cytotoxic hydroxyl radical $(-\mathrm{OH})$ or superoxide radicals $\left(\mathrm{O}_{2}{ }^{\circ}\right)$. These in turn induce lipid peroxidation, resulting in increased cell membrane fluidity and cell degeneration. ${ }^{57-59}$ Under normal circumstances, hydrogen peroxide in the brain is inactivated by glutathione peroxidase in the presence of its ratelimiting substrate, reduced glutathione. Both PD and MPTPinduced parkinsonism are associated with decreased levels of glutathione, ${ }^{60.62}$ potentially rendering the brain more vulnerable to damage from free radicals. At the same time, levels of iron are elevated more than two-fold in PD substantia nigra, ${ }^{61,63,64}$ potentially increasing the generation of free radicals. More specifically, it is iron (III) that is significantly increased in PD, resulting in a shift of the iron (II)/iron (III) ratio in favour of iron (III). It was recently demonstrated that neuromelanin, which is traditionally regarded as a scavenger of free radicals, may instead increase the rate of $-\mathrm{OH}$ production if the predominant form of iron is iron (III). ${ }^{65}$ This selective increase of iron (III) in PD substantia nigra shifts the ratio of iron (II)/iron (III) from the 3:1 ratio seen in normals towards $1: 1,61$ which is the optimal ratio for initiation of $-\mathrm{OH}$ formation and membrane lipid peroxidation. ${ }^{66,67}$ The result is that in both MPTP-induced toxicity and PD there may be increased production of free radicals and a decrease in scavenging enzymes. One of the objectives of the multicentre DATATOP study is to examine whether alpha-tocopherol, a component of vitamin $E$ which is known to trap free radicals, $, 99,68$ might retard the progression of idiopathic
PD. The data are not yet sufficiently conclusive to permit a statement concerning its potential efficacy. ${ }^{2}$

\section{EnVironmental Neurotoxins and PD}

The knowledge that PD is probably not genetically transmitted 69 and the ability of MPTP to mimic the features of idiopathic PD have given rise to the idea that PD may be caused by an environmental substance similar in structure to MPTP. 70 Support for this notion has come from clinical studies, animal experimentation and epidemiological investigations. An early case report was that of a chemist who developed PD at age 37, eight years after beginning to work with MPTP. ${ }^{71}$ A PET scan study of asymptomatic subjects who had self-administered MPTP in low doses showed decreased striatal 6-fluorodopa activity. ${ }^{72}$ More recently, 22 individuals with a mean age of 34.7 years and a history of exposure to MPTP have been found to exhibit signs of mild parkinsonism..$^{73}$

Additional evidence in support of the "environmental hypothesis" has come from animal experimentation. While none of the commonly occurring environmental contaminants that are structurally similar to MPTP has thus far been shown to produce a parkinsonian syndrome, ${ }^{74-76}$ several laboratory-synthesized analogues of MPTP have demonstrated a capacity for killing dopamine neurons. The expression of cytotoxicity by some of these compounds is dependent upon their oxidation by MAO-A instead of MAO-B. 77

Epidemiological studies have found that idiopathic PD is more prevalent in industrialized than in nonindustrialized countries and, within the former, more prevalent in rural than in urban areas. ${ }^{70}$ One possible interpretation of these findings is that environmental factors such as drinking well water or exposure to pesticides and herbicides may contribute to the pathogenesis of PD. ${ }^{70,77.78}$

\section{Towards a Preventative Therapy for PD}

The hypothesis behind the recent trials of deprenyl in early PD was that the pathogenesis of PD might involve a neurotoxic process analogous to that involved in MPTP-induced cytotoxicity. While the initial reports give hope that deprenyl may indeed be able to delay the clinical progression of PD 1.2 this issue remains controversial. An alternative explanation for the apparent efficacy of deprenyl in early PD might be that deprenyl simply provides symptomatic relief to PD patients, by inhibiting the breakdown of dopamine in presynaptic terminals. This possibility was carefully considered by the authors of the DATATOP study, but was rejected. A double-blind trial of deprenyl therapy in patients with PD who were not taking levodopa found it to be of little if any symptomatic benefit. ${ }^{79}$ Furthermore, among the patients studied in double-blind fashion by Tetrud and Langston and in the DATATOP study, there was no change in parkinsonian or depression scores among deprenyl-treated patients either when drug treatment was started ("wash-in") or when it was stopped ("wash-out").1.2 It has been pointed out, however, that the one-month wash-out period used by Tetrud/Langston and the DATATOP investigators may not have been adequate, as the pharmacological effects of deprenyl may persist for more than one month after its withdrawal.80-82 The recent decision to extend the DATATOP wash-out period should help clarify 
whether the effect of deprenyl is primarily symptomatic, or whether it indeed slows the course of PD.

The precise relationship between MPTP-induced parkinsonism and idiopathic PD remains, at this point, unclear. One possibility is that idiopathic PD develops from a process exactly analogous to that of MPTP-induced toxicity. In that case, one would expect to be able to inhibit the progression of PD by interfering with any of the 5 steps outlined in Figure 1. Among the drugs which block MPTP toxicity, only deprenyl has been systematically studied in PD patients. Whether chloroquine or a dopamine uptake inhibitor might be effective in delaying the progression of PD symptoms is unknown. Another possibility is that the putative effect of deprenyl may be related to its ability to inhibit the oxidative stress associated with increased dopamine turnover in the early stages of PD. 83 The oxidation of dopamine by MAO-B, however, would appear to take place outside of dopaminergic neurons, since MAO-B in brain seems to be present only in glia and in serotonergic neurons. 30,31 One would therefore expect that the selective MAO-B inhibitor, deprenyl, would selectively inhibit oxidative free radical formation in nondopaminergic cells, as opposed to the melanized dopaminergic neurons which are targeted in PD. Given that dopamine appears to be deaminated by MAO-A as well as by MAO-B, ${ }^{31,32}$ one wonders whether a nonspecific MAO inhibitor might not be even more effective than deprenyl in treating patients with early PD.

\section{ACKNOWLEDGEMENTS}

Supported by the Grants to MFM from the Parkinson Foundation of Canada and the MRC. JCSF holds a Postgraduate Scholarship from NSERC. MFM is a Career Scientist of the Ontario Ministry of Health.

\section{REFERENCES}

I. Tetrud JW, Langston JW. The effect of deprenyl (selegiline) on the natural history of Parkinson's Disease. Science 1989; 245 : 519 . 522.

2. Parkinson Study Group. Effect of deprenyl on the progression of disability in early Parkinson's Disease. N Engl J Med 1989; 321: 1364-1371.

3. Birkmayer W, Knoll J, Riederer P, et al. Increased life expectancy resulting from addition of deprenyl to madopar treatment in Parkinson's disease: A long-term study. J Neural Transm 1985; 65: 113-127.

4. Lees AJ, Shaw KM, Kohout LJ, et al. Deprenyl in Parkinson's disease. Lancet 1977; ii: 791-795.

5. Rinne UK. Deprenyl (selegiline) in the treatment of Parkinson's disease. Acta Neurol Scand Suppl 1983; 95: 107-111.

6. Csanda E, Tarczy M. Clinical evaluation of deprenyl (selegiline) in the treatment of Parkinson's Disease. Acta Neurol Scand Suppl 1983; 95: 117-122.

7. Knoll J. The possible mechanisms of action of $(-)$ deprenyl in Parkinson's disease. J Neural Transm 1978; 43: 177-198.

8. Birkmayer W, Knoll J, Riederer P, et al. (-) Deprenyl leads to prolongation of L-dopa efficacy in Parkinson's disease. Mod Prob in Pharmacopsych, 1983; 19: 170-176.

9. Langston JW, Ballard P, Tetrud JW, et al. Parkinsonism due to a product of meperidine-analog synthesis. Science 1983; 219: 979 980 .

10. Langston JW, Irwin I, Langston EB, et al. MPTP-Induced parkinsonism in humans: A review of the syndrome and observations relating to the phenomenon of tardive toxicity. $I n$ : Markey, SP et al. eds. MPTP: A neurotoxin producing a Parkinsonian syndrome. New York: Academic Press, 1986; 9-22.

11. Marini AM, Schwartz JP, Kopin IJ. The neurotoxicity of 1-methyl4-phenylpyridinium in cultured cerebellar granule cells. J Neurosci 1989; 9: 3665-3672
12. Forno LS, Langston JW, DeLanney LE, et al. Locus coeruleus lesions and eosinophilic inclusions in MPTP-treated monkeys. Ann Neurol 1986; 20: 449-455.

13. Allen MJ, Cross AJ, Yeats JC, et al. Neuropeptides and dopamine in the marmoset: Effect of treatment with 1-methyl-4-phenyl1,2,3,6-tetra-hydropyridine (MPTP). Brain 1986; 109: 143-157.

14. Hallman H, Lange J, Olson L, et al. Neurochemical and histochemical characterization of neurotoxic effects of 1-methyl-4-phenyl1,2,3,6-tetrahydropyridine on brain catecholamine neurones in the mouse. J Neurochem 1985; 44(1): 117-127.

15. Heikkila RE, Sonsalla PK. The use of the MPTP-treated mouse as an animal model of Parkinsonism. Can J Neurol Sci, Suppl 1987; 14(3): 436-440.

16. Sonsalla PK, Heikkila RE. The influence of dose and dosing interval on MPTP-induced dopaminergic neurotoxicity in mice. Eur J Pharmacol 1986; 129: 339-345.

17. German GC, Dubach M, Askari S, et al. 1-methyl-4-phenyl1,2,3,6-tetrahydropyridine-induced Parkinsonian syndrome in Macaca fascicularis: which midbrain dopaminergic neurons are lost? Neurosci 1988; 24(1): 161-174.

18. Melamed E, Rosenthal J, Globus M, et al. Mesolimbic dopaminergic neurons are not spared by MPTP neurotoxicity in mice. Eur J Pharmacol 1985; 114: 97-100.

19. Ghilardi MF, Chung E, Bodis-Wollner I, et al. Systemic 1-methyl4-phenyl-1,2,3,6-tetrahydropyridine (MPTP) administration decreases retinal dopamine content in primates. Life Sci 1988; 43: $255-262$

20. Forno LS, DeLanney LE, Irwin I, et al. Neuropathology of MPTP. treated monkeys: Comparison with the neuropathology of human idiopathic Parkinson's disease. In: Markey, SP et al, eds. MPTP: A Neurotoxin Producing a Parkinsonian Syndrome, New York: Academic Press 1986; 119-140.

21. Mitchell IJ, Cross AJ, Sambrook MA, et al. Sites of the neurotoxic action of 1-methyl-4-phenyl-1,2,3,6-tetrahydropyridine in the macaque monkey include the ventral tegmental area and the locus coeruleus. Neurosci Lett 1985; 61: 195-200.

22. Mayer RA, Kindt V, Heikkila RE. Prevention of the nigrostriatal toxicity of 1-methyl-4-phenyl-1,2,3,6-tetrahydropyridine by inhibitors of 3,4-dihydroxyphenylethylamine transport. J Neurochem 1986; 47(4); 1073-1079.

23. Chiba K, Trevor A, Castagnoli N. Metabolism of the neurotoxic tertiary amine, MPTP, by brain monoamine oxidase. Biochem Biophys Res Comm 1984; 120(2): 574-578.

24. Langston JW. Mechanisms of MPTP toxicity: More answers, more questions. Trends Pharmacol Sci 1985; 6(9): 375-378.

25. Fuller RW, Hemrick-Luecke SK. Influence of selective reversible inhibitors of monoamine oxidase on the prolonged depletion of striatal dopamine by 1-methyl-4-pheny!-1,2,3,6-tetrahydropyridine in mice. Life Sci 1985; 37(12): 1089-1096.

26. Heikkila RE, Manzino L, Cabbat FS, et al. Protection against the dopaminergic neurotoxicity of 1-methyl-4-phenyl-1,2,3,6tetrahydropyridine by monoamine oxidase inhibitors. Nature 1984; 311 : 467-469.

27. Sundström E, Jonsson G. Pharmacological interference with the neurotoxic action of 1-methyl-4-phenyl-1,2,3,6-tetrahydropyridine (MPTP) on central catecholamine neurons in the mouse. Eur J Pharmacol 1985; 110: 293-299.

28. Mytilineou C, Friedman L. Studies on the metabolism and toxicity of 1-methyl-4-phenyl-1,2,3,6-tetrahydropyridine in cultures of embryonic rat mesencephalon. J Neurochem 1988; 51: 750-755.

29. Demarest KT, Smith DJ, Azzaro AJ. The presence of the type A form of monoamine oxidase within nigrostriatal dopamine-containing neurons. J Pharmacol Exp Ther 1980; 215(2): 461-468.

30. Levitt P, Pintar JE, Breakfield XO. Immunocytochemical demonstration of monoamine oxidase $\mathrm{B}$ in brain astrocytes and serotonergic neurons. Proc Natl Acad Sci, USA 1982; 79: 6385-6389.

31. Westlund KN, Denney RM, Kochersperger LM, et al. Distinct monoamine oxidase $\mathrm{A}$ and $\mathrm{B}$ populations in primate brain. Science 1985; 230: 181-183.

32. Stenström A, Sundström E, Fowler CJ. Comparison of intra- and extrasynaptosomal monoamine oxidase- $\mathrm{A}$ and $-\mathrm{B}$ activities in the striatum and frontal cortex of two mice strains with different 
sensitivities to neurotoxic actions of 1-methyl-4-phenyl-1,2,3,6tetrahydropyridine. Pharmacol Toxicol 1989; 64: 276-281.

33. Brooks WJ, Jarvis MF, Wagner JC. Attenuation of MPTP-induced dopaminergic neurotoxicity by a serotonin uptake blocker. J Neural Transm 1988; 71: 85-90.

34. Brooks WJ, Jarvis MF, Wagner JC. Astrocytes as a primary locus for the conversion of MPTP into MPP+. J Neural Transm 1989; 76: $1-12$.

35. Ransom BR, Kunis DM, Irwin I, et al. Astrocytes convert the parkinsonism inducing neurotoxin, MPTP, to its active metabolite, MPP+. Neurosci Lett 1987; 75: 323-328.

36. Javitch JA, Snyder SH. Uptake of MPP+ by dopamine neurons explains selectivity of Parkinsonism-inducing neurotoxin MPTP. Eur J Pharmacol 1984; 106: 455-456.

37. Javitch JA, D'Amato RJ, Strittmatter SM, et al. Parkinsonisminducing neurotoxin, 1-methyl-4-phenyl-1,2,3,6-tetrahydropyridine: Uptake of metabolite $\mathrm{N}$-methyl-4-phenylpyridinium by dopamine neurons explains selective toxicity. Proc Natl Acad Sci, USA 1985; 82: 2173-2177.

38. Pileblad E, Carlsson A. Catecholamine-uptake inhibitors prevent the neurotoxicity of 1-methyl-4-phenyl-1,2,3,6-tetrahydropyridine (MPTP) in mouse brain. Neuropharmacology 1985; 24(7): 689-692.

39. Ricaurte GA, Langston JW, DeLanney LE, et al. Dopamine uptake blockers protect against the dopamine depleting effect of 1 methyl-4-phenyl-1,2,3,6-tetrahydropyridine (MPTP) in the mouse striatum. Neurosci Lett 1985; 59:259-264.

40. Schinelli S, Zuddas A, Kopin IJ, et al. 1-methyl-4-phenyl-1,2,3,6tetrahydropyridine metabolism and 1-methyl-4-phenylpyridinium uptake in dissociated cell cultures from the embryonic mesencephalon. J Neurochem 1988; 50: 1900-1907.

41. Fuller RW, Hemrick-Luecke SK, Perry KW. Deprenyl antagonizes acute lethality of 1-methyl-4-phenyl-1,2,3,6-tetrahydropyridine in mice. J Pharmacol Exp Ther 1988; 247(2): 531-535.

42. Reinhard JF, Daniels AJ, Viveros $\mathrm{OH}$. Potentiation by reserpine and tetrabenazine of brain catecholamine depletions by MPTP ( I-methyl-4-phenyl-1,2,3,6-tetrahydropyridine) in the mouse: evidence for subcellular sequestration as basis for cellular resistance to the toxicant. Neurosci Lett 1988; 90: 349-353.

43. Barden $\mathrm{H}$. The biology and chemistry of neuromelanin. in RS Sohal, ed. Age Pigments. Amsterdam: Elsevier, 1981: 155-180.

44. D’Amato RJ, Alexander GM, Schwartzman RJ, et al. Evidence for neuromelanin involvement in MPTP-induced neurotoxicity. Nature 1987; 327: 324-326.

45. D'Amato RJ, Alexander GM, Schwartzman RJ, et al, Neuromelanin: A role in MPTP-induced neurotoxicity. Life Sci 1987; 40: 705-712.

46. D'Amato RJ, Benham DF, Snyder SH. Characterization of the binding of $\mathrm{N}$-methyl-4-phenylpyridine, the toxic metabolite of the parkinsonian neurotoxin $\mathrm{N}$-methyl-4-phenyl-1,2,3,6-tetrahydropyridine, to neuromelanin. J Neurochem 1987; 48: 653-658.

47. Levi AC, DeMattei M, Ravazzani R, et al. Effects of 1-methyl-4phenyl-1,2,3,6-tetrahydropyridine (MPTP) on ultrastructure of nigral neuromelanin in Macaca fascicularis. Neurosci Lett 1989; 96: $27 !-276$.

48. Bankiewicz KS, Oldfield EH, Chiueh CC, et al. Hemiparkinsonism in monkeys after unilateral internal carotoid artery infusion of 1methyl-4-phenyl-1,2,3,6-tetrahydropyridine (MPTP). Life Sci 1986; 39(1): 7-16.

49. Bédard PJ, Di Paolo T, Falardeau P, et al. Chronic treatment with L-dopa, but not bromocriptine, induces dyskinesia in MPTPparkinsonian monkeys: Correlation with $\left[{ }^{3} \mathrm{H}\right]$ spiperone binding. Brain Res 1986; 379: 294-299.

50. Crossman AR, Clarke CE, Boyce S, et al. MPTP-induced Parkinsonism in the monkey: Neurochemical pathology, complication of treatment and pathophysiological mechanisms. Can J Neurol Sci, Suppl 1987; 14(3): 428-435.

51. Ramsay RR, Singer TP. Energy-dependent uptake of N-MPTP, by mitochondria. J Biol Chem 1986; 261: 7585-7587.

52. Singer TP, Ramsay RR, McKeown K, et al. Mechanism of the neurotoxicity of 1 -methylphenylpyridinium (MPP+), the toxic bioactivation product of I-methyl-4-phenyl-1,2,3,6-tetrahydropyridine (MPTP). Toxicology 1988; 49: 17-23.
53. Vyas I, Heikkila RE, Nicklas WJ. Studies on the neurotoxicity of Imethyl-4-phenyl-1,2,3,6-tetrahydropyridine: Inhibition of NADlinked substrate oxidation by its metabolite, 1-methyl-4phenylpyridinium. J Neurochem 1986; 46: 1501-1507.

54. Schapira AHV, Cooper JM, Dexter D, et al. Mitochondrial complex I deficiency in Parkinson's Disease. J Neurochem 1990; 54: 823827.

55. Parker WD, Boyson SJ, Parks JK. Abnormalities of the electron transport chain in idiopathic Parkinson's disease. Ann Neurol 1989; 26: 719-723.

56. Graham D. On the origin and significance of neuromelanin. Arch Path Lab Med 1979; 103: 359-362.

57. Halliwell B, Gutteridge JMC. Free radicals in biology and medicine. Clarendon Press, Oxford. 1985.

58. Halliwell B, Gutteridge JMC. Oxygen free radicals and iron in relation to biology and medicine: some problems and concepts. Arch Biochem Biophys 1986; 246: 501-514.

59. Halliwell B, Gutteridge JMC. Oxygen radicals and the nervous system. Trends Neurosci 1985; 8: 22-26.

60. Perry TL, Godin DV, Hansen S. Parkinson's disease: A disorder due to nigral glutathione deficiency? Neurosci Lell 1982; 33: 305-310.

61. Riederer P, Sofic E, Rausch WD, et al. Transition metals, ferritin, glutathione and ascorbic acid in parkinsonian brain. J Neurochem 1989; 52: 515-520.

62. Yong VW, Perry TL, Krisman AA. Depletion of glutathione in brainstem of mice caused by $\mathrm{N}$-methyl-4-phenyl-1,2,3,6-tetrahydropyridine. Neurosci Lett 1986; 63: 56-60.

63. Earle KM. Studies on Parkinson's disease including X-ray fluorescent spectroscopy of formalin-fixed brain tissue. J Neuropathol Exp Neurol 1968; 27: 1-14.

64. Dexter DT, Wells FR, Agid F, et al. Increased nigral iron content in postmortem parkinsonian brain. Lancet 1987: ii: 1219-1220.

65. Pilas B, Sana T, Kalyanaraman B, et al. The effect of melanin on iron associated decomposition of hydrogen peroxide. Free Rad Biol Med 1988; 4: 285-293.

66. Braughler JM, Duncan LA, Chang RL. The involvement of iron in lipid peroxidation: Importance of ferric to ferrous ratio in initiation. J Biol Chem 1986; 261: 10282-10289.

67. Minotti G, Aust SD. The requirement for iron (III) in the initiation of lipid peroxidation by iron (II) and hydrogen peroxide. J Biol Chem 1987; 262: 1098-1104.

68. Willson RL. Free radical protection: Why vitamin $E$, not vitamin $C$. beta-carotene or glutathione? In Biology of vitamin E. Ciba Foundation Symposium 101 1983; 19-44.

69. Duvoisin RC. Is Parkinson's disease acquired or inherited? Can J Neurol Sci Supplement 1984; 11(1): 15I-155.

70. Tanner CM. The role of environmental toxins in the etiology of Parkinson's disease. Trends Neurosci 1989; 12(2): 49-54.

71. Langston JW, Ballard PA. Parkinson's disease in a chemist working with I-methyl-4-phenyl-1,2,3,6-tetrahydropyridine. N Engl J Med 1983; 309-310.

72. Calne DB, Langston JW, Martin WRW, et al. Positron emission tomography after MPTP: Observations relating to the cause of Parkinson's disease. Nature 1985; 317: 246-249.

73. Tetrud JW, Langston JW, Garbe PL, et al. Mild parkinsonism in persons exposed to 1-methyl-4-phenyl-1,2,3,6-tetrahydropyridine (MPTP). Neurology 1989; 39: 1483-1487.

74. Perry TL, Jones K, Hansen S, et al. 4-Phenylpyridine and three other analogues of 1 -methyl-4-phenyl-1,2,3,6-tetrahydropyridine lack dopaminergic nigrostriatal neurotoxicity in mice and marmosets. Neurosci Lett 1987; 75: 65-70.

75. Perry TL, Jones K, Hansen S, et al. 2-phenylpyridine and 3phenylpyridine, constituents of tea, are unlikely to cause idiopathic Parkinson's disease. J Neurol Sci 1988; 85: 309-317.

76. Perry TL, Yong VW, Wall RA, et al. Paraquat and two endogenous analogues of the neurotoxic substance $\mathrm{N}$-methyl-4-phenyl1,2,3,6-tetrahydropyridine do not damage dopaminergic nigrostriatal neurons in the mouse. Neurosci Lett 1986; 69: 285-289.

77. Heikkila RE, Kindt MV, Sonsalla PK, et al. Importance of monoamine oxidase $A$ in the bioactivation of neurotoxic analogs of 1-methyl-4-phenyl-1,2,3,6-tetrahydropyridine. Proc Nat Acad Sci, USA 1988; 85: 6172-6176. 
78. Koller W, Vetere-Overfield B, Gray C, et al. Environmental risk factors in Parkinson's disease. Neurology 1990; 40: 1218-1221.

79. Teräväinen H. Selegiline in Parkinson's disease. Acta Neurol Scand 1990; 81: 333-336.

80. Zweig RM, Carmichael JM, Morrill GB. Deprenyl for the treatment of early Parkinson's disease (letter). New Engl J Med 1990; 322: 1526.

81. Oreland L, Johannson F, Ekstedt J. Dose regimen of deprenyl (selegiline) and platelet MAO activities. Acta Neurol Scand Suppl 1983; 95: 87-89.
82. Arnett DC, Fowler JS, MacGregor RR, et al. Turnover of brain monoamine oxidase measured in vivo by positron emission tomography using L- $\left[{ }^{1} \mathrm{C}\right]$ deprenyl. J Neurochem 1987; 49: 522-527.

83. Cohen G, Spina MB. Deprenyl suppresses the oxidative stress associated with increased dopamine turnover. Ann Neurol 1989; 26: 689-690. 